\title{
Integración de las universidades de frontera de los Departamentos de Guajira y Cesar de Colombia, y del Estado Zulia de Venezuela.
}

\author{
Rafael L. Espinoza Rodríguez \\ espinozarl@yahoo.com \\ Universidad del Zulia /Maracaibo-Venezuela \\ Leonor Castrillo Guerra \\ castrilloleonor@gmail.com \\ Universidad Popular del Cesar/ Valle de Upar-Colombia
}

\section{Resumen}

La inexistencia de una real integración de las regiones de frontera venezolana y colombiana, y en consecuencia la falta de políticas y estrategias institucionales para soportar las relaciones entre universidades de frontera, mediante alianzas formales, constituye la razón de la investigación. El estudio se propone, desde su línea central de argumentación teórica, establecer los significados culturales de la integración y su correlación con los procesos de integración de las universidades localizadas en regiones interfronterizas, y diagnosticar los niveles de viabilidad y factibilidad para la creación una estructura de integración interuniversitaria, que conlleve a la transferencia de conocimiento, innovación y desarrollo tecnológico. La investigación es Descriptiva-Explicativa, con enfoques analítico, explicativo e interpretativo. Se realizó orientadas en secuencia lógica desde la construcción de un sistema teórico que es la base del diagnóstico de campo realizado a partir de tres universidades interfronterizas. Los resultados de la investigación permitieron evaluar las potencialidades de éxito del proceso y estrategias de integración y relacionamiento con las organizaciones universitarias de frontera de alcance internacional partiendo de la conformación de alianzas de conocimiento.

\section{Palabras clave}

Integración, universidades de frontera, relaciones interinstitucionales.

Recibido 10/08/2019 - 12/09/2019 


\title{
Integration of the border universities of the Departments of Guajira and Cesar of Colombia, and of the Zulia State of Venezuela.
}

\begin{abstract}
The lack of real integration of the Venezuelan and Colombian border regions, and consequently the lack of institutional policies and strategies to support relations between border universities, through formal alliances, is the reason for the investigation. The study proposes, from its central line of theoretical argumentation, to establish the cultural meanings of integration and its correlation with the processes of integration of universities located in cross-border regions, and to diagnose the levels of viability and feasibility for the creation of a structure of interuniversity integration, which leads to the transfer of knowledge, innovation and technological development. The research is descriptive-explanatory, with analytical, explanatory and interpretative approaches. It was conducted in logical sequence from the construction of a theoretical system that is the basis of the field diagnosis made from three cross-border universities. The results of the research allowed us to evaluate the potentialities of success of the process and integration and relationship strategies with international border university organizations based on the formation of knowledge alliances.
\end{abstract}

\section{Keywords}

Integration, border universities, interinstitutional relations 


\section{Integração das universidades de fronteira dos departamentos de Guajira e Cesar da Colômbia e do estado de Zulia da Venezuela.}

\section{Resumo}

A falta de integração real das regiões fronteiriças da Venezuela e da Colômbia e, consequentemente, a falta de políticas e estratégias institucionais para apoiar as relações entre as universidades fronteiriças, por meio de alianças formais, é o motivo da investigação. O estudo propõe, a partir de sua linha central de argumentação teórica, estabelecer os significados culturais da integração e sua correlação com os processos de integração de universidades localizadas em regiões transfronteiriças e diagnosticar os níveis de viabilidade e viabilidade para a criação de uma estrutura de integração interuniversitária, que leva à transferência de conhecimento, inovação e desenvolvimento tecnológico. A pesquisa é descritivo-explicativa, com abordagens analíticas, explicativas e interpretativas. Foi conduzido em seqüência lógica a partir da construção de um sistema teórico que é a base do diagnóstico de campo realizado em três universidades transfronteiriças. Os resultados da pesquisa nos permitiram avaliar as potencialidades de sucesso do processo e estratégias de integração e relacionamento com organizações universitárias internacionais de fronteira com base na formação de alianças de conhecimento.

\section{Palavras chave}

Integração, universidades fronteiriças, relações interinstitucionais. 


\section{Introducción}

El reconocimiento que se hace de los procesos de integración entre países que definen amplias zonas de frontera, conduce a discurrir sobre la necesidad de observar los diversos contextos de integración que deben ser atendidos. En este sentido la integración se soporta en ámbitos tales como: integración política, social, cultural, económica, y educativa.

Es común considerar la integración mayormente desde el ámbito político y económico, prestando poca atención a la integración por la vía de los procesos educativos. Si bien la educación en particular ha ofrecido, desde las organizaciones universitarias, los aportes concernientes en el ámbito político y económico, también se destacan los acuerdos internacionales, fundamentalmente para el desarrollo de la formación de profesionales en áreas prioritarias, como las científicas y las ingenierías, insistiendo en la participación de las universidades de diversos países, así como también las demandas de producción de conocimiento requerido para la disposición de innovaciones tecnológicas.

Un diagnóstico general de experiencias de integración, desde la Educación Superior, entre Colombia y Venezuela, está reflejado en los acuerdos que hacen la historia de nuestras relaciones fronterizas, entre ellos el Informe de la Misión Mixta Colombia-Venezuela y el Banco Interamericano (BID), titulado: "Posibilidades de integración Fronteriza ColombiaVenezuela" (1964), donde se manifiesta la ausencia de prácticas sostenidas de relaciones interinstitucionales, desde los gobiernos nacionales y regionales, para iniciar diseño e implementación de estrategias que conlleven al establecimiento de acuerdos que sustenten la formación de profesionales en el nivel de pregrado y posgrado, con movilidad internacional. Destaca también la poca atención a la formulación de proyectos de investigación, innovación tecnológica y emprendimiento entre universidades localizadas en las zonas fronterizas, como son aquellas ubicadas en el estado Zulia (Venezuela) y los departamentos Guajira y Cesar (Colombia).

Entendiendo que el desarrollo del talento humano y de la producción de innovaciones con base en la investigación científica y tecnológica, es fundamental para el desarrollo económico, social, cultural y político de ambos países, se demanda consolidar procesos de 
integración que comprometan su desarrollo. Por tanto, es de urgencia que los gobiernos de estos países adelanten procesos de construcción de alianzas que faciliten la movilidad académica, científica y tecnológica de las organizaciones universitarias. Dado el rol que cumplen las universidades en cuanto a asegurar la producción del conocimiento para el desarrollo del talento, para reponer las necesidades de innovación, desde nuestra experiencia como gente de frontera, es determinante que estas instituciones se aboquen a la tarea de tejer redes que permitan adelantar acciones orientadas hacia apoyar a los gobiernos de ambos países en la comprensión de las estrategias de tal integración.

La globalización, como proceso que afecta a todos los países del mundo y por tanto a Colombia y Venezuela, ha dado lugar a que los países se integren para desarrollar fortalezas con base en nuevos conocimientos y tecnologías para actuar en la sociedad y en la economía del conocimiento. En este orden de ideas, la internacionalización de las universidades constituye un requisito para interactuar en el mundo globalizado, dado que las relaciones internacionales llevan consigo una serie de supuestos en las dimensiones académicas, políticas, sociales y económicas, las cuales conducen a la identificación de escenarios de alto impacto para el logro de relaciones exitosas en esta aldea global.

La inexistencia de una verdadera integración regional, nacional e internacional, y con ello la falta de políticas y estrategias institucionales formales, para soportar relaciones entre universidades a través de la conformación de alianzas de conocimiento, la deficiente infraestructura tecnológica y de equipos para interrelacionarse con universidades del exterior y los escasos recursos financieros para acceder a participar en convocatorias internacionales, constituyen algunos de los aspectos que nos llevan a plantear la siguiente tesis:

La integración de las universidades de frontera venezolana -colombiana en el ámbito académico y científico para la transferencia de conocimiento e innovación, está determinada por la existencia de estructuras interinstitucionales, así como valores interculturales de los contextos regionales universitarios y de los propósitos de internacionalización de las universidades. 


\section{Objetivos del Estudio}

- Definir los elementos epistemológicos que fundamentan las explicaciones teóricas del proceso de integración entre las universidades de frontera.

- Caracterizar las relaciones de alcance internacional entre las universidades de frontera a través de la transferencia de conocimiento, innovación y desarrollo tecnológico.

\section{Metódica de Investigación}

Entre explicación y comprensión, entre disciplinariedad y transdisciplinariedad, se asume una perspectiva epistemológica de naturaleza ecléctica y programática que va a soportar el proceso de investigación. En esta perspectiva, lo social, lo económico y lo educativo convergen como dimensiones básicas para el análisis, con el auxilio de otras dimensiones de naturaleza histórica, cultural e interpretativa, imprescindibles para la argumentación del conocimiento. Desde esta perspectiva epistemológica en la cual se integran los criterios básicos del racionalismo deductivo, la crítica inductiva y el constructivismo para estructurar la investigación, se establece el sistema teórico como referente para la búsqueda del conocimiento y el alcance de los objetivos propuestos. La definición de dicha perspectiva requiere de un anclaje filosófico que brinde sustento a la concepción paradigmático del objeto de estudio, constituido en este caso por las relaciones de integración entre las universidades de frontera, transferencia de conocimiento, y la internacionalización.

En consonancia con la filosofía racionalista crítica se proponen los enfoques: analítico, explicativo e interpretativo, como bases argumentativas seleccionadas para el abordaje del problema, tomando en cuenta que la problemática estudiada forma parte de una realidad. Al sentido paradigmático de la investigación corresponden posturas epistemológicas modernas y postmodernas que delimitan la construcción del sistema teórico, permitiendo validar adicionalmente el conjunto de técnicas y procedimientos necesarios para concretar las etapas del proceso de investigación. Se asume la complementariedad paradigmática de métodos cualitativos y cuantitativos para visualizar de forma más amplia la realidad fronteriza, caracterizada por una coherencia interna y una unidad que es esencial 
a su naturaleza, enmarcada en acontecimientos y actuaciones individuales y colectivas que proyectan sus significados y construyen su identidad.

La fase de observación empírica, se concibió para caracterizar la infraestructura de relacionamiento, valorar las diferentes expresiones de la integración y sus incidencias en el desarrollo regional fronterizo y en el proceso de internacionalización.

Se utilizó la técnica de encuesta, diseñando un cuestionario de tipo estructurado y de opciones múltiples, el cual fue construido para obtener información de las variables consideradas en la promoción del desarrollo social, la producción, y el fortalecimiento de la identidad cultural en la región fronteriza Colombia- Venezuela. El cuestionario fue validado teóricamente por expertos. Se consideró como población instituciones universitarias localizadas a lado y lado de la región fronteriza correspondiendo al departamento Cesar y Guajira en Colombia y al estado Zulia en Venezuela.

Cuando se requirió más información se complementó con entrevistas no estructuradas y luego recolectadas utilizando un instrumento de registro de respuesta para la generación del juicio colectivo por consenso acerca de las denominadas variables promotoras de las fuerzas dinamizadoras del desarrollo social, económico, educativo y político de la región fronteriza, las cuales fueron utilizadas para validar algunas referencias empíricas.

\section{Sistema Teórico Explicativo}

Implicaciones de los Procesos de Formación de la Interculturalidad en la Interacción de Regiones de Fronteras: Venezuela-Colombia 


\section{Ilustración 2. Mapa Teórico Conceptual}



Fuente: Espinoza R. Rafael L. y Castrillo, Leonor (2018)1

Para la integración de territorios, donde existen elementos sociales en común como: el idioma, el origen histórico, las prácticas religiosas, los hábitos alimenticios, las celebraciones artístico-artesanales, etc.; es necesario identificar profundamente los factores y las dinámicas que potencian o impiden esa integración. Como ejemplo de ellos, se tiene el respeto a las diferencias.

Después de la identificación esos factores y dinámicas, se deben determinar estrategias de integración, o procesos denominados, en el léxico sociológico, como tejer 
puentes o puntos de encuentro (cultura académica universitaria, sistemas gerenciales universitarios y otros). Esos puentes tienen necesariamente que conducir a la reducción o eliminación de los factores y dinámicas obstaculizadoras, los cuales entorpecen el proceso general; que fue diseñado para lograr la formación holística de la diversidad cultural, representada ésta por esos elementos.

La interculturalidad por alcanzar debe pasar por los procesos mencionados de forma coordinada y secuencial; sin alterar la aplicación de los pasos respectivos. La razón de ello es que se puede complicar y, así, retardar la consecución de los vínculos culturales diferentes; los cuales se desean articular; como se evidencia, en especial, en las zonas limítrofes Venezuela-Colombia. Además, es un requisito básico que los pasos del proceso general sean definitivamente formalizados; de manera que, al observar los mismos, sean adecuadamente monitoreados, desde las organizaciones universitarias de frontera.

\section{El Contexto de la Interculturalidad como Ámbito para la Participación de las Organizaciones Universitarias en la Integración venezolana - colombiana.}

La interculturalidad holística, por lograr, asume características propias; las cuales le van a dar un marco de especificidad; por tener las universidades de la frontera venezolanacolombiana rasgos distintivos, que las separan del resto de las Latinoamericanas. Los elementos comunes que diferencian aquellas de éstas, se encuentran especialmente en los dialectos; los cuales se hablan en esa área fronteriza, teniendo ellos una raíz Caribe. Así mismo, en relación al mundo de las ideas, significados, creencias, costumbres, actitudes, habilidades y emocionalidades, ellos se distinguen de las otras agrupaciones indígenas de América Latina.

Por otra parte, el entorno social de la frontera venezolana-colombiana ha experimentado modificaciones que le brindan actualmente un toque de modernidad. Este es el caso del uso amplio de las nuevas tecnologías de la comunicación e información, lo cual permite un acceso factible hacia la internacionalización de las organizaciones universitarias de esta zona fronteriza.

En cuanto al aspecto infraestructural, a su vez existen diferencias con otras áreas fronterizas latinoamericanas y hemisféricas; sobre todo en el tipo de viviendas, áreas 
comerciales y de servicios. En lo referente al ambiente organizacional, éste también presenta marcas que lo diferencia de otros, debido al predomino de dinámicas menos complejas. La ubicación de las poblaciones en la periferia de los Estados-Nación implica una situación de frontera en dos ámbitos: el geopolítico y el del conocimiento, un lugar privilegiado tanto para la integración y la autonomía organizativa como para la reproducción de conocimientos propios de la comunidad. La frontera se constituye entonces en el lugar de mediación y negociación de tales procesos.

Es en este sentido donde la interculturalidad aparece como la posibilidad de diálogo entre las comunidades, permitiendo zonas de contacto que generan el intercambio y la cooperación desde sus aprendizajes. Fluyen los conocimientos y experiencias entre aquellos que buscan la construcción critica de nuevos escenarios sociales, políticos, económicos y culturales, en la frontera colombo-venezolana cuyo entorno social ha experimentado, modificaciones que le brindan actualmente un toque de modernidad.

Ello es a partir del uso amplio de las nuevas tecnologías de la comunicación e información, referenciado en la Conferencia Regional de Educación Superior en América Latina y el Caribe (2008), donde se propuso, la formulación de una agenda regional fronteriza en materia de ciencia, tecnología e innovación, políticas de evaluación, acreditación y aseguramiento de la calidad de las universidades de la región que permitan superar las brechas, entre los Estados-Nación y fomento del desarrollo sostenible, de acuerdo a los requerimientos de las reformas educativas que cada país viene adelantando para el desarrollo de la educación superior.

\section{Naturaleza y Alcance de las Instituciones de Educación Superior en Colombia}

Es bien conocido que cada época propugna sus ideales educativos, en Colombia con el cambio de la constitución de 1991 y la reforma a las universidades con la ley 30, la cual viene a regular la educación superior, a pesar de un ambiente de severas restricciones financieras y profundos cambios económicos en el ámbito mundial, se da un reconocimiento de adaptar y modernizar la universidad en su estructura, organización y modelos educativos que atiendan a la demanda del desarrollo científico tecnológico y del mercado profesional, dando así autonomía a las instituciones de educación superior, para que desarrollen y tracen 
su propio rumbo vinculando la universidad con el estado social de derecho, consagrando su libertad y abriendo espacios para la participación teniendo en cuenta el siguiente articulado contenido en la ley 30 de 1992:

La educación superior es un servicio público, cultural e inherente a la finalidad, del Estado (ley 30, art.2).

El Estado en conformidad con la constitución política de Colombia y con la presente ley garantiza la autonomía universitaria y vela por la calidad de los servicios educativos a través del ejercicio de la suprema inspección y vigilancia de la educación superior (ley 30, art 3).

Cada universidad adoptará en su estatuto general una estructura que comprenda entre otras la existencia de un Consejo superior Universitario (C.S.), un Consejo Académico (C.A) y el Rector, como órganos de dirección y gobierno que representaran al Estado y a la comunidad académica de la universidad (ley 30, capítulo II art.62).

De acuerdo con la política de descentralización consagrada en la constitución política de Colombia, créanse los Comité Regionales de Educación Superior (CRES) como organismo asesor del consejo nacional de educación superior (ley30, art.133).

Por tanto, las instituciones de educación superior son las entidades que cuentan con arraigo a las normas legales, con el reconocimiento oficial como prestadoras de servicio público de la educación superior en territorio colombiano. Según su carácter académico se clasifican en instituciones técnicas profesionales, instituciones tecnológicas y universidades y, según la naturaleza jurídica en pública o privada. El personal docente puede ser de dedicación exclusiva, de tiempo completo y su incorporación es previo concurso público de méritos y su salario será de acuerdo al escalafón ya sea como auxiliar, asistente, asociado titular.

Incide en esta reforma universitaria, la reformulación que planteó la Comisión de Ciencia y Tecnología (1987) Colciencias, empresarios privados y organismos internacionales respecto a que la investigación se formule dentro de la política científica 
enmarcada por las demandas del sector productivo y al mismo tiempo ser el elemento básico en la formación universitaria.

Un balance a la reforma de 1992, mostró una gran preocupación por la calidad de la educación y los indicadores de eficiencia (investigación y acreditación), la unidad nacional, la descentralización, la integración regional y la cooperación interinstitucional, la profesionalización de la actividad docente con autorregulación y estímulos a la producción académica. Dada la complejidad. del balance, se amplía la estructura del Ministerio de Educación Nacional y se crea el Viceministerio de Educación Superior (decreto 2230 del. 2003) con dos direcciones: calidad y fomento a la educación superior.

Para dar garantía en los temas de evaluación, certificación y acreditación de la calidad de la educación superior en Colombia se crea dentro del Viceministerio de Educación Superior el Sistema de Aseguramiento de la Calidad de la Educación Superior, conformado por tres componentes relacionados entre sí, información, evaluación y fomento y con ellas los organismos, las acciones y las estrategias que aplican desde el proceso mismo de creación y establecimiento de una institución de educación superior hasta el desempeño del profesional que egresa del sistema.

Las referencias presentadas permiten considerar la existencia de fundamentos legales para promover la integración internacional de las universidades colombianas.

\section{Naturaleza y alcance de las Instituciones de Educación Superior en Venezuela.}

La identidad propia de la región fronteriza Venezuela-Colombia nos permite destacar las características más resaltantes de la educación superior en Venezuela a través de su historia pero, sobre todo, su evolución (1990-2001), periodo este caracterizado por un alto volumen y un crecimiento acelerado de dicha actividad, la existencia de una gran heterogeneidad y desarticulación institucional y una gran preocupación por la postergación de soluciones a los problemas de pertinencia, calidad, financiamiento y vicios jurídicos de esta actividad.

A mediados del siglo XX se inician procesos de incorporación en el país de instituciones universitaria, las cuales impulsaron en 1958 la aprobación y promulgación de la ley de 
universidades, instrumento que marcó un hito en la historia de la educación superior venezolana, cuya vigencia fue de doce años. Este texto legislativo fue modificado y en 1970 se sanciona y promulga un nuevo instrumento legal, producto de los cambios políticos, sociales y económicos suscitados en esa década en el país, la esencia de su misión está contenida en el artículo 3 que establece:

Las universidades deben realizar una función rectora en la educación, cultura y la ciencia. Para cumplir esta misión, sus actividades se dirigirán a crear, asimilar y difundir el saber mediante la investigación y la enseñanza; a completar la formación integral iniciada en los ciclos educacionales anteriores; y a formar los equipos profesionales y técnicos que necesita la nación para su desarrollo y progreso (Gaceta Oficial No. 1429, Extraordinaria del 8 de septiembre de 1970).

Sin embargo, en el texto de la mencionada ley, el legislador no incorpora, en la redacción de las normas, elementos asociados a la cooperación universitaria nacional e internacional, ni a estrategias de interrelación con otras universidades; únicamente contiene aspectos de organización, funciones, deberes y derechos de las universidades; entre los cuales destacan el sistema electoral universitario; redefine el concepto de autonomía fijando limites en los aspectos organizativo, académico, administrativo y financiero, otorga mayores poderes al Consejo Nacional de Universidades (CNU) e introduce la idea de planificación nacional, por la cual se crea la oficina de Planificación del Sector Universitario (OPSU), como organismo de asesoría técnica del CNU en la materia.

Además de restringir la autonomía institucional conforma un conjunto heterogéneo y doblemente binario de educación superior: universidades vs. Institutos de educación superior (que no son universidades) por un lado y sector oficial vs. sector privado por el otro. Lo que hacía imposible la estructuración de un verdadero sistema nacional.

Los fines y el financiamiento de la educación superior en Venezuela están definidos en la Constitución Nacional (1999) en un conjunto variado de leyes y reglamentos entre los cuales destacan la Ley orgánica de Educación, la Ley Orgánica de Administración Central y la Ley de Universidades, todas destacan:

El Estado reconoce la autonomía universitaria como principio y jerarquía que permite a la comunidad académica dedicarse a la búsqueda del 


\section{Integración Intercultural de Universidades de Región de Frontera}

No obstante, no haberse consolidado un proceso de integración socioeducativo y científico-tecnológico entre las universidades localizadas en la región de frontera, se han dado relaciones entre ellas, lo cual podría favorecer el inicio de la integración de mayor alcance. Para precisar el conocimiento que tienen los representantes de las universidades muestreadas respecto a los logros generales que se obtendrían de prácticas de integración llevadas a cabo entre Venezuela y Colombia, se les solicitó los identificaran. En la Tabla No. 1 se recoge que la gestión del conocimiento y la transferencia de conocimiento serían los logros inmediatos que podrían generarse a partir de la integración intercultural de las universidades localizadas en la región de frontera. Esta apreciación puede deberse al hecho que los contactos intermitentes que en ocasiones tiene esas universidades se ha dado por medio de acuerdos para la oferta de formación de postgrado por parte de la Universidad del Zulia a profesores de las dos universidades colombianas.

Tabla 1. Logros generales del proceso de integración bilateral que se trata de implementar.

\begin{tabular}{|l|c|}
\hline \multicolumn{1}{|c|}{ Logros cumplidos } & Mediana \\
\hline Inclusión de nuevas regiones en la estructura de la Identidad Cultural & Poco \\
\hline $\begin{array}{l}\text { Nuevas funciones del Sistema de Integración Cultural Producción de } \\
\text { conocimiento }\end{array}$ & Algo \\
\hline $\begin{array}{l}\text { Nuevas funciones del Sistema de Integración Cultural Transferencia de } \\
\text { conocimiento }\end{array}$ & Mucho \\
\hline $\begin{array}{l}\text { Nuevas funciones del Sistema de Integración Cultural gestión del } \\
\text { conocimiento }\end{array}$ & Mucho \\
\hline Nuevo Sistema de Integración Cultural & Algo \\
\hline Nuevo orden de integración fronterizo & Algo \\
\hline
\end{tabular}

Fuente: L. Castrillo y R. Espinoza (2018).

Para ampliar la información se diagnosticó si se han dado a partir de experiencias de integración logros organizacionales al interior de cada una de las universidades, al respecto lo datos de la Tabla No. 2 indican que de acuerdo a la opinión integrada de la muestra de los miembros de las tres universidades, no se han dado cambios significativos orientados hacia la integración interuniversitaria, lo cual confirma que las relaciones académicas que se han dado 
mediante la formación de postgrado sólo constituye la ejecución de un servicio ante una solicitud por parte de una de ellas.

Tabla 2. Logros internos generados por la integración interuniversitaria

\begin{tabular}{|l|c|}
\hline Tipo de logros & Mediana \\
\hline Reconocimiento intercultural & Algo \\
\hline Inclusión entre culturas & Poco \\
\hline Cohesión intercultural & Algo \\
\hline Completitud de la interculturalidad & Poco \\
\hline Satisfacción intercultural & Poco \\
\hline Eficiencia intercultural & Poco \\
\hline Pluralismo intercultural & Algo \\
\hline
\end{tabular}

Fuente: L. Castillo y R. Espinoza (2018)

La integración de las universidades localizadas en la región de frontera venezolana y colombiana por su naturaleza de integración internacional podría conducir y permitir logros de gran alcance e impacto, igualmente nacional e internacional, es decir más allá de la región de frontera. Las tres universidades tiempo atrás han firmado convenios genéricos que contemplan desarrollar acciones académicas, científicas y tecnológicas por tal razón se supuso que tal formalización de interacción habría generado resultados positivos respecto a la producción de conocimiento. Los datos de la Tabla No. 3 revelan todo lo contrario, de medianamente suficiente a insuficiente es la valoración que se le otorga al cumplimiento y logro de resultados.

Tabla 3. Logros del proceso de integración internacional interuniversitario

\begin{tabular}{|l|l|}
\hline Tipo de Conocimiento & \multicolumn{1}{|c|}{ Mediana } \\
\hline Cientifico & Medianamente suficiente \\
\hline Tecnológico & Medianamente suficiente \\
\hline Académico & Medianamente suficiente \\
\hline Económico & Insuficiente \\
\hline Educativo & Medianamente suficiente \\
\hline Social & Insuficiente \\
\hline Político & Insuficiente \\
\hline Cultural-Artístico & Medianamente suficiente \\
\hline
\end{tabular}

Fuente: L. Castrillo y R. Espinoza (2018). 


\section{Asociatividad Interuniversitaria}

El proceso de integración de las universidades de frontera por su complejidad requiere que tales organizaciones asuman el compromiso de la asociatividad, lo cual implica considerar cambios internos en la percepción y valoración que se tiene del otro. En ese sentido ocurre que cuando se tiene una valoración positiva de la contraparte se empieza a configurar la confianza y la disposición hacia la conducta de reciprocidad. Esta referencia teórica marco la pauta para identificar las organizaciones con que la universidad se relacionaba y la frecuencia con que lo hacía. En la Tabla No 4, se recoge la data que indica que las tres universidades limitan sus relaciones con organismos gubernamentales y no gubernamentales locales y regionales. Igualmente se destaca que las tres universidades se marginan de la integración internacional. Este dato se puede interpretar de manera diferente, pero sin lugar a duda refleja una conducta de poca iniciativa para establecer relaciones de alcance internacional, posiblemente por no confiar en sus potencialidades, capacidades y productos y servicios para mostrar y compartir.

El proceso de integración de las universidades de frontera por su complejidad requiere que tales organizaciones asuman el compromiso de la asociatividad, lo cual implica considerar cambios internos en la percepción y valoración que se tiene del otro. En ese sentido ocurre que cuando se tiene una valoración positiva de la contraparte se empieza a configurar la confianza y la disposición hacia la conducta de reciprocidad. Esta referencia teórica marco la pauta para identificar las organizaciones con que la universidad se relacionaba y la frecuencia con que lo hacía. En la Tabla No 4, se recoge la data que indica que las tres universidades limitan sus relaciones con organismos gubernamentales y no gubernamentales locales y regionales. Igualmente se destaca que las tres universidades se marginan de la integración internacional. Este dato se puede interpretar de manera diferente, pero sin lugar a duda refleja una conducta de poca iniciativa para establecer relaciones de alcance internacional, posiblemente por no confiar en sus potencialidades, capacidades y productos y servicios para mostrar y compartir. 
Tabla 4. Nivel de relaciones de integración interorganizacional de alcance nacional e internacional

\begin{tabular}{|l|c|}
\hline \multicolumn{1}{|c|}{ Organizaciones } & Mediana \\
\hline Organismos gubernamentales & Casi siempre \\
\hline No gubernamentales & Casi siempre \\
\hline Organismos bilaterales & A veces \\
\hline Organismos miltilaterales & Casi nunca \\
\hline Agencias de ccoperación & Casi nunca \\
\hline Orras & No respondió \\
\hline
\end{tabular}

Fuerte: L. Castrillo y R. Espinoza (2018)

Ampliando la información respecto a la conducta de integración asociativa de las tres universidades en la Tabla No. 5 se expone el tiempo de duración de la relación con los organismos, en promedio no pasa del año, lo cual significa que son relaciones de poco alcance, por tanto, no llegan a ser relaciones de cooperación y menos de ser relaciones en el contexto de una red interorganizacional.

\section{Tabla 5 Duración de las relaciones de integración interorganizacional}

\begin{tabular}{|l|c|}
\hline \multicolumn{1}{|c|}{ Organizaciones } & Mediana \\
\hline Organismos gubernamentales & 18 a 24 meses \\
\hline No gubernamentales & 18 a 24 meses \\
\hline Organismos bilaterales & 18 a 24 meses \\
\hline Organismos multilaterales & 12 a 18 meses \\
\hline Agencias de cooperación & 18 a 24 meses \\
\hline Otras & No respondió \\
\hline
\end{tabular}

Fuente: L. Castrillo y R. Espinoza (2018)

La densidad de la integración de las universidades de frontera se puede estimar considerando el número de organizaciones con las cuales se relaciona, en la Tabla No. 6 se puede observar que entre las tres universidades sólo una universidad, la Universidad del Zulia informa haber establecido vínculos en el rango de 76 a 100 organizaciones, prorrogando la relación en un $80 \%$. 
Tabla 6 Densidad de la integración de las universidades

\begin{tabular}{|l|c|c|c|c|c|}
\hline \multicolumn{1}{|c|}{ Cantidad de organizaciones } & $\mathbf{f}_{\mathbf{r}}$ & $\%$ & $\begin{array}{c}\% \text { de las } \\
\text { prorrogas }\end{array}$ & $\mathbf{f}_{\mathbf{r}}$ & $\%$ \\
\hline 10 a 25 organizaciones & 2 & 40,0 & 30 & 1 & 20,0 \\
\hline 20 a 50 organizaciones & 2 & 40,0 & 50 & 1 & 20,0 \\
\hline 51 a 75 organizaciones & 0 & 0.0 & & & 1 \\
\hline 76 a 100 organizaciones & 1 & 20,0 & 80 & 20,0 \\
\hline Más de 100 organizaciones & 0 & 0.0 & & & $50 \%$ con prorroga \\
\hline
\end{tabular}

Fuente: L. Castrillo Y R. Espinoza (2018)

La modalidad y la cantidad de las relaciones establecidas refleja el alcance e impacto de las mismas, en el cuadro No. 7 se puede distinguir que la modalidad de relación denominada vinculación, que es relación de corto plazo, mayormente unidireccional y de poco impacto para el desarrollo de innovaciones tecnológicas y emprendimiento económicos con base en la innovación, es la que las tres universidades han llevado a cabo en mayor cantidad.

Tabla. 7 Cantidad de modalidad de relaciones sostenidas

\begin{tabular}{|l|c|c|c|c|c|c|c|c|c|c|c|}
\hline \multirow{2}{*}{$\begin{array}{l}\text { Modalidad de } \\
\text { relación }\end{array}$} & \multicolumn{2}{|c|}{$\mathbf{1} \mathbf{a} \mathbf{4}$} & \multicolumn{2}{|c|}{$\mathbf{5}$ a 9 } & \multicolumn{2}{|c|}{$\mathbf{1 0} \mathbf{a} \mathbf{~ 1 4}$} & \multicolumn{2}{|c|}{$\mathbf{1 5}$ a 20 } & \multicolumn{2}{|c|}{ Más de 20 } & \multirow{2}{*}{ Mediana } \\
\cline { 2 - 12 } & $\mathbf{f}_{\mathrm{r}}$ & $\%$ & $\mathbf{f}_{\mathrm{r}}$ & $\%$ & $\mathbf{f}_{\mathrm{r}}$ & $\mathbf{\%}$ & $\mathbf{f}_{\mathrm{r}}$ & $\%$ & $\mathbf{f}_{\mathrm{r}}$ & $\%$ & \\
\hline Vinculación & & & 1 & 20,0 & 1 & 20,0 & & & 1 & 20,0 & Más de 20 \\
\hline Asociación & & & 2 & 40,0 & & & 1 & 20,0 & & & 15 a 20 \\
\hline Cooperación & 1 & 20,0 & & & 2 & 40,0 & & & & & 10 a 14 \\
\hline
\end{tabular}

Fuente: L. Castrillo y R. Espinoza (2018)

\section{Reciprocidad e Integración Interuniversitaria}

La reciprocidad es un concepto práctico en las relaciones internacionales. El principio de reciprocidad en lo que respecta a las relaciones internacionales y tratados de esta índole, se refiere a que las garantías, beneficios y sanciones que un Estado otorga a los ciudadanos o personas jurídicas de otro Estado, deben ser retribuidos por la contraparte de la misma forma. 
Cuando usamos la categoría de reciprocidad, siguiendo a Mauss (2002), estamos ante una paradoja porque se trata de participaciones libres y gratuitas, pero que al mismo tiempo son obligatorias e interesadas, ellas instituyen el contrato o la obligación de devolver lo que ha sido entregado como prestación, y su desempeño moral permite un "fenómeno humano que se produce en todas las sociedades conocidas", o sea: el mercado. Según el mismo autor, este fenómeno también nos ayuda a reconocer sus diferentes expresiones, por ejemplo, habría un mercado propiamente de prestaciones y contraprestaciones, al cual llamamos reciprocidad.

La práctica de la reciprocidad en las universidades estudiadas se puede observar en los datos presentados en las tablas No.8 y No 9, en ella se registra el tipo de obligaciones asumidas, la proporción de su cumplimiento y el tipo de beneficios logrados recíprocamente. Se hace visible que las obligaciones se corresponden con las señaladas en el texto de los convenios genéricos firmados, pero que con frecuencia no se ejecutan.

Tabla 8. Proporción de obligaciones Acordadas

\begin{tabular}{|c|c|c|c|c|c|c|c|c|c|c|c|}
\hline \multirow[t]{2}{*}{ Obligaciones } & \multicolumn{2}{|c|}{$\begin{array}{l}\text { Menos } \\
10 \%\end{array}$} & \multicolumn{2}{|c|}{$\begin{array}{c}\text { Entrel0\% } \\
\text { y } 40 \%\end{array}$} & \multicolumn{2}{|c|}{$\begin{array}{c}\text { Entre } 40 \% \\
\text { y } 60 \%\end{array}$} & \multicolumn{2}{|c|}{$\begin{array}{c}\text { Entre } 60 \% \\
\text { y } 80 \%\end{array}$} & \multicolumn{2}{|c|}{$\begin{array}{l}\text { Mas de } \\
80 \%\end{array}$} & \multirow[t]{2}{*}{ Mediana } \\
\hline & $f_{r}$ & $\%$ & $f_{r}$ & $\%$ & $f_{r}$ & $\%$ & $f_{r}$ & $\%$ & $\mathbf{f}_{r}$ & $\%$ & \\
\hline $\begin{array}{l}\text { Intercambio de personal docente } \\
\text { administrativo y estudiantes }\end{array}$ & & & 2 & 40,0 & 1 & 20,0 & 1 & 20,0 & & & 40 a $60 \%$ \\
\hline $\begin{array}{l}\text { Ejecución de proyectos de } \\
\text { investigación }\end{array}$ & 1 & 20,0 & 1 & 20,0 & 2 & 40,0 & & & & & 40 a $60 \%$ \\
\hline Publicaciones conjuntas & 1 & 20,0 & 1 & 20,0 & 2 & 40,0 & 1 & 20,0 & & & 40 a $60 \%$ \\
\hline $\begin{array}{l}\text { Uso de equipos tecnológicos e } \\
\text { infraestructuras }\end{array}$ & 2 & 40,0 & 1 & 20,0 & 2 & 40,0 & & & & & 10 a $40 \%$ \\
\hline Emprendimientos Tecnológicos & 2 & 40,0 & 1 & 20,0 & 2 & 40,0 & & & & & 10 a $40 \%$ \\
\hline Patentes registradas & 5 & 100,0 & & & & & & & & & Menos $10 \%$ \\
\hline $\begin{array}{l}\text { Conformación de equipos de } \\
\text { investigación y desarrollo }\end{array}$ & 2 & 40,0 & 2 & 40,0 & & & 1 & 20,0 & & & 10 a $40 \%$ \\
\hline $\begin{array}{l}\text { Ejecución de programas de } \\
\text { posgrado }\end{array}$ & 1 & 20,0 & 2 & 40,0 & & & 1 & 20,0 & 1 & 20,0 & 10 a $40 \%$ \\
\hline Otro tipo. & & & & & & & & & & & No respondió \\
\hline
\end{tabular}

Fuente: L. Castrillo y R. Espinoza (2018) 
Tabla 9. Proporcionalidad de los beneficios recibidos

\begin{tabular}{|c|c|c|c|c|c|c|c|c|c|c|c|}
\hline \multirow[t]{2}{*}{ Beneficios } & \multicolumn{2}{|c|}{$\begin{array}{c}\text { Menos } \\
10 \%\end{array}$} & \multicolumn{2}{|c|}{$\begin{array}{c}\text { Entre } \\
10 \% \text { y } \\
40 \%\end{array}$} & \multicolumn{2}{|c|}{\begin{tabular}{|} 
Entre $40 \%$ \\
y $60 \%$
\end{tabular}} & \multicolumn{2}{|c|}{$\begin{array}{c}\text { Entre } \\
60 \% \text { y } \\
80 \%\end{array}$} & \multicolumn{2}{|c|}{$\begin{array}{l}\text { Más de } \\
\mathbf{8 0} \%\end{array}$} & \multirow[t]{2}{*}{ Mediana } \\
\hline & $\mathbf{f}_{\mathbf{r}}$ & $\%$ & $\mathbf{f}_{\mathbf{r}}$ & $\%$ & $\mathbf{f}_{\mathrm{r}}$ & $\%$ & $\mathbf{f}_{\mathbf{r}}$ & $\%$ & $\mathbf{f}_{\mathbf{r}}$ & $\%$ & \\
\hline $\begin{array}{l}\text { Personal docente de investigación, } \\
\text { administrativo y estudiantes } \\
\text { formados }\end{array}$ & 1 & 20,0 & 1 & 20,0 & & & 3 & 60, & & & 60 a $80 \%$ \\
\hline Proyecto de investigación ejecutados & 1 & 20,0 & & & 3 & 60,0 & 1 & 20,0 & & & 40 a $60 \%$ \\
\hline $\begin{array}{l}\text { Proyectos de investigación } \\
\text { financiados }\end{array}$ & 1 & 20,0 & 1 & 20,0 & 3 & 60,0 & & & & & 40 a $60 \%$ \\
\hline Compartimiento de Innovaciones & 4 & 80,0 & & & & & & & & & Menos $10 \%$ \\
\hline $\begin{array}{l}\text { Explotación de Innovaciones } \\
\text { Tecnológicas }\end{array}$ & 4 & 80,0 & & & & & & & & & Menos $10 \%$ \\
\hline Publicaciones conjuntas realizadas & 1 & 20,0 & 2 & 40,0 & 1 & 20,0 & 1 & 20,0 & & & 10 a $40 \%$ \\
\hline Revistas arbitradas & 2 & 40,0 & 3 & 60,0 & & & & & & & 10 a $40 \%$ \\
\hline Dotación de artículos tecnológicos & 3 & 60,0 & 1 & 20,0 & & & & & & & Menos $10 \%$ \\
\hline Mantenimiento de infraestructura & 3 & 60,0 & 1 & 20,0 & & & & & & & Menos $10 \%$ \\
\hline $\begin{array}{l}\text { Fortalecimiento de estudios de } \\
\text { posgrado }\end{array}$ & 1 & 20,0 & 2 & 40,0 & 1 & 20,0 & 1 & 20,0 & & & 10 a $40 \%$ \\
\hline Otro tipo. & & & & & & & & & & & No respondió \\
\hline
\end{tabular}

\section{Confianza y Credibilidad Inteorganizacional}

Entre las muchas aproximaciones a la definición y la naturaleza de la confianza, Mayer, Shoorman y David (1995) la concibe como la buena voluntad de una persona de ser vulnerable a las acciones de otra, basada en la expectativa de que ésta realizará una acción determinada importante para quien confía, sin tener que llegar a controlar y monitorear dicha acción.

Niklas Luhmann (2005) desde un enfoque mucho más allá del sociológico, la entiende como un requerimiento operacional clave para que la sociedad no se vea abocada al caos o al miedo, retardando e incluso paralizando la capacidad de decisión a todo nivel. ...], la confianza surge cada vez que nos encontramos en una situación de relativa vulnerabilidad caracterizada por la incertidumbre y la falta de comunicación. Cuando no contamos con información perfecta o la misma es muy costosa, las decisiones y acciones racionales se vuelven imposibles. En dichos casos quedamos paralizados, a menos que recurramos a la confianza. Es decir, pese a que la información y los datos con que contamos no nos permiten predecir con exactitud lo que 
ocurrirá, y por ende, nos vemos imposibilitados de tener expectativas positivas o de actuar racionalmente, igualmente decidimos hacerlo. La confianza no es una percepción o intuición innecesaria que utilizamos en situaciones de cálculo de riesgo, sino que la usamos cuando no es posible establecer dicho cálculo.

En la tabla No. 10 se puede observar que las tres universidades estudiadas muestran tener mayor nivel de confianza entre sus pares universitarias y las organizaciones gubernamentales, el valor medio alto, se puede interpretar que responden al hecho que entre ellas existen antecedentes de relaciones por la vía de convenios.

Tabla 10. Nivel de confianza en las organizaciones

\begin{tabular}{|l|c|}
\hline Organizaciones & Mediana \\
\hline Organizaciones universitarias colombianas & Medio alto \\
\hline Organizaciones universitarias venezolanas & Medio alto \\
\hline Organizaciones gubernamentales & Medio alto \\
\hline Organizaciones no gubernamentales & Medio \\
\hline Organismos bilaterales & Medio bajo \\
\hline Organismos multilaterales & Medio bajo \\
\hline Agencia de Cooperación al Desarrollo & Medio bajo \\
\hline Otro tipo & No respondió \\
\hline
\end{tabular}

Fuente: L. Castrillo y R. Espinoza (2018)

En lo que respecta a la credibilidad interorganizacional, tradicionalmente, se plantea que ésta se compone de dos dimensiones: capacidad de generar confianza y grado de conocimiento, donde ambas poseen componentes objetivos y subjetivos. Es decir, la capacidad de generar confianza es un juicio de valor que emite el receptor basado en factores subjetivos como las afinidades éticas, ideológicas o estéticas. En forma similar el grado de conocimiento puede ser percibido en forma subjetiva, aunque también incluye características relativas objetivas, referentes a indicadores indirectos sobre los conocimientos expertos de la fuente (por ejemplo, acreditaciones académicas o profesionales, prestigio, trayectoria) o del rigor del mensaje (calidad de la información, exahustividad, referenciación).

La Tabla No 11 recoge los datos respecto al nivel de credibilidad que le otorgan las universidades de la muestra a otras organizaciones. Al respecto llama la atención el valor de confianza que le otorgan a las universidades venezolanas. 
Tabla 11. Nivel de credibilidad en las organizaciones

\begin{tabular}{|l|c|c|}
\hline \multicolumn{1}{|c|}{ Organizaciones } & Nivel de credibilidad & $\begin{array}{c}\text { Proceso del nivel de } \\
\text { credibilidad durante los } \\
\text { últimos cinco años }\end{array}$ \\
\cline { 2 - 3 } & & Mediana \\
\hline Organizaciones universitarias Venezolanas & Moderadamente alto & Aumento \\
\hline Organizaciones gubernamentales & Moderadamente alto & Aumento \\
\hline Organizaciones no gubernamentales & Moderadamente alto & Aumento \\
\hline Organismos bilaterales & Moderado & Aumento \\
\hline Organismos multilaterales & Moderadamente bajo & Aumento \\
\hline Agencia de Cooperación al Desarrollo & Moderadamente bajo & Aumento \\
\hline Otro tipo. Indique. & No respondió & No respondió \\
\hline
\end{tabular}

Fuente: L. Castrillo y R. Espinoza (2018)

Institucionalización de la Integración Interuniversitaria La integración interuniversitaria debe responder a la integración intercultural por tanto ésta transciende la conducta particular, discrecional de las personas en funciones del relacionamiento internacional en las organizaciones, para concebir formas pertinentes y factibles de alianzas resguarda mediante la aplicación y cumplimiento del sistema de leyes, normas y reglamentos para proteger los compromisos asumidos. En la Tabla No. 12 se reúnen los datos correspondientes a los acuerdos que las tres universidades han asumido. Se debe resaltar que hay un explícito reconocimiento del marco institucional que le da carácter formal y de sostenibilidad a los convenios conducentes a la integración interuniversitaria.

La formalización de la integración de las universidades localizadas en la región de frontera implica desarrollar una cultura institucional, esto constituye asumir cumplir con un sistema regulatorio que conlleva a la convivencia, el bienestar y la minimización de conflictos interorganizacionales. En la Tabla No 13 se destacan los datos que reflejan el tipo de normas que regulan las actividades socio económicas, científicas, tecnológicas, educacionales, políticas y culturales que sostiene la universidad. De acuerdo a los académicos muestreados su universidad de pertenencia tiene un alto nivel de cumplimiento institucional. 
Tabla 12. Nivel de acuerdo que existe en la organización

\begin{tabular}{|l|c|}
\hline \multicolumn{1}{|c|}{ Sistema Institucional } & Mediana \\
\hline $\begin{array}{l}\text { Al respetarse las leyes, normas y reglamentos en las operaciones organizacionales } \\
\text { existe mayor seguridad en la obtención de beneficios }\end{array}$ & Satisfactorio \\
\hline $\begin{array}{l}\text { El cumplimiento de las leyes, normas y reglamentos garantiza las relaciones } \\
\text { interorganizacionales }\end{array}$ & Satisfactorio \\
\hline $\begin{array}{l}\text { El aumento del número de normas y reglas para las relaciones comerciales incrementa } \\
\text { la seguridad organizacional }\end{array}$ & Satisfactorio \\
\hline $\begin{array}{l}\text { El aumento del número de normas y reglas para las relaciones científicas y } \\
\text { tecnológicas incrementa la seguridad organizacional }\end{array}$ & Satisfactorio \\
\hline $\begin{array}{l}\text { Los principios y valores de buena conducta son indispensables para las relaciones } \\
\text { interorganizacionales. }\end{array}$ & Satisfactorio \\
\hline
\end{tabular}

Fuente: L. Castrillo y R. Espinoza (2018)

Tabla 13. Tipos de normas que regulan las actividades socio económicas, científicas, tecnológicas, educacionales, políticas y culturales.

\begin{tabular}{|l|c|c|c|c|c|c|c|c|c|c|c|}
\hline \multirow{2}{*}{ Normas formales e informales } & \multicolumn{2}{|c|}{$l$} & \multicolumn{2}{|c|}{$\mathbf{2}$} & \multicolumn{2}{|c|}{3} & \multicolumn{2}{c|}{4} & \multicolumn{2}{|c|}{5} & \multirow{2}{*}{ Mediana } \\
\cline { 2 - 11 } & $\mathbf{f}_{\boldsymbol{r}}$ & $\%$ & $\mathbf{f}_{\mathbf{r}}$ & $\%$ & $\mathbf{f}_{\mathbf{r}}$ & $\%$ & $\mathbf{f}_{\mathbf{r}}$ & $\%$ & $\mathbf{f}_{\mathbf{r}}$ & $\%$ & \\
\hline Leyes & & & 1 & 20,0 & & & & & 4 & 80,0 & 5 \\
\hline Decretos & & & & & & & 2 & 40,0 & 3 & 60,0 & 5 \\
\hline Reglamentos & & & & & 1 & 20,0 & 1 & 20,0 & 3 & 60,0 & 5 \\
\hline Estatutos generales & & & & & & & 1 & 20,0 & 4 & 80,0 & 5 \\
\hline Normas técnicas & & & & & & & 2 & 40,0 & 3 & 60,0 & 5 \\
\hline Acuerdos del sector & & & & & 1 & 20,0 & 1 & 20,0 & 3 & 60,0 & 5 \\
\hline
\end{tabular}

Fuente: L. Castrillo y R. Espinoza (2018)

El progreso que pueda alcanzar en el espectro de alianzas interorganizacionales las tres universidades estudiadas se puede estimar con base a los logros pautados y alcanzados entre ellas. En la Tabla No. 14 y No. 15 se recoge los datos que exponen la naturaleza de acuerdos formales e informales que pueden darse entre las organizaciones y/o agrupaciones, que se relacionan en el medio en el cual participa la organización universitaria. Las alianzas de conocimiento y las alianzas de emprendimientos empresariales interuniversitarios destacan entre las de mayor probabilidad.

El alcance de los acuerdos establecidos entre las organizaciones se expresa en los beneficios compartidos, para conocer qué beneficios habrían alcanzado o podrían alcanzar las 
universidades se solicitó los detallaran, al respecto en la Tabla No. 16 se presentan los datos correspondientes. Hay un claro consenso de que los beneficios serian económicos y sociales.

Tabla 14. Acuerdos formales que puedan darse entre las organizaciones y/o agrupaciones.

\begin{tabular}{|l|c|c|c|c|c|c|c|c|c|c|c|c|c|}
\hline Naturaleza de acuerdos formales & \multicolumn{2}{|c|}{$\mathbf{l}$} & \multicolumn{2}{|c|}{$\mathbf{2}$} & \multicolumn{2}{|c|}{$\mathbf{3}$} & \multicolumn{2}{|c|}{$\mathbf{5}$} & Mediana \\
\hline & $\mathbf{f}_{\mathrm{r}}$ & $\mathbf{6}$ & $\mathbf{f}_{\mathrm{r}}$ & $\mathbf{\%}$ & $\mathbf{f}_{\mathrm{r}}$ & $\mathbf{\%}$ & $\mathbf{f}_{\mathrm{r}}$ & $\mathbf{\%}$ & $\mathbf{f}_{\mathrm{r}}$ & $\mathbf{\%}$ & \\
\hline Procesos jurídicos & 1 & 20,0 & & & 1 & 20,0 & 1 & 20,0 & 2 & 40,0 & 4 \\
\hline Comunicación y asuntos públicos & 1 & 20,0 & & & 1 & 20,0 & 3 & 60,0 & & & 4 \\
\hline Transferencia tecnológica & 1 & 20,0 & 1 & 20,0 & 1 & 20,0 & 2 & 40,0 & & & 3 \\
\hline Alianzas de Conocimiento & & & 2 & 40,0 & & & 2 & 40,0 & 1 & 20,0 & 4 \\
\hline Alianzas de Innovación Tecnológica & & & 2 & 40,0 & 2 & 40,0 & & & 1 & 20,0 & 3 \\
\hline $\begin{array}{l}\text { Emprendimientos Empresariales } \\
\text { Interuniversitarios }\end{array}$ & & & 2 & 40,0 & & & 2 & 40,0 & 1 & 20,0 & 4 \\
\hline $\begin{array}{l}\text { Emprendimientos Económicos Universidad- } \\
\text { Empresa }\end{array}$ & 1 & 20,0 & 2 & 40,0 & 1 & 20,0 & 1 & 20,0 & & & 2 \\
\hline Adquisición de divisas & 3 & 60,0 & 1 & 20,0 & 1 & 20,0 & & & & & 1 \\
\hline Adquisición de insumos y materias primas & 1 & 20,0 & 2 & 40,0 & 2 & 40,0 & & & & & 2 \\
\hline $\begin{array}{l}\text { Copatrocinio de programas de desarrollo social, } \\
\text { educativo, sanitario, económico a nivel } \\
\text { internacional }\end{array}$ & 1 & 20,0 & 1 & 20,0 & 2 & 40,0 & & & & & 3 \\
\hline Otro. & & & & & & & & & & & \\
\hline
\end{tabular}

Fuente: L. Castrillo y R. Espinoza(2018)

Tabla 15 Acuerdos informales que puedan darse entre las organizaciones y/o agrupaciones

\begin{tabular}{|l|l|l|l|l|l|l|l|l|l|l|l|l|l|}
\hline \multirow{2}{*}{ Naturaleza de acuerdos informales } & \multicolumn{2}{|c|}{$\mathbf{l}$} & \multicolumn{2}{|c|}{$\mathbf{2}$} & \multicolumn{2}{|c|}{$\mathbf{3}$} & \multicolumn{2}{|c|}{$\mathbf{4}$} & \multicolumn{2}{|c|}{5} & Mediana \\
\hline & fr & $\%$ & fr & $\%$ & fr & $\%$ & fr & $\%$ & fr & $\%$ & \\
\hline $\begin{array}{l}\text { Asistencia a organismos sin fines de } \\
\text { lucro }\end{array}$ & 1 & 20,0 & 1 & 20,0 & 1 & 20,0 & 1 & 20,0 & 1 & 20,0 & 3 \\
\hline $\begin{array}{l}\text { Asesoria a organismos públicos para } \\
\text { Diseñar políticas y programas de desarrollo. }\end{array}$ & & & 2 & 40,0 & 2 & 40,0 & 1 & 20,0 & & & 3 \\
\hline $\begin{array}{l}\text { Diagnósticos socioeconómicos promovidos por } \\
\text { organismos públicos y privados }\end{array}$ & 1 & 20,0 & 1 & 20,0 & 1 & 20,0 & 2 & 40,0 & & & 3 \\
\hline $\begin{array}{l}\text { Intermediación para acceder a fuentes de } \\
\text { financiamiento }\end{array}$ & 1 & 20,0 & 2 & 40,0 & 2 & 40,0 & & & & & 2 \\
\hline $\begin{array}{l}\text { Donación de recursos generados por la } \\
\text { universidad }\end{array}$ & 2 & 40,0 & 1 & 20,0 & 2 & 40,0 & & & & & 2 \\
\hline Otro & & & & & & & & & & & No respondió \\
\hline
\end{tabular}

Fuente: L. Castrillo y R. Espinoza(2018) 
Tabla 16. Beneficios de las actividades

\begin{tabular}{|c|c|c|c|c|c|c|c|c|}
\hline \multirow{3}{*}{ BENEFICIOS } & \multicolumn{8}{|c|}{ ACTIVIDADES } \\
\hline & \multicolumn{2}{|c|}{ Económicas } & \multicolumn{2}{|c|}{ Políticas } & \multicolumn{2}{|c|}{ Culturales } & \multicolumn{2}{|c|}{ Sociales } \\
\hline & $f_{1}$ & $\%$ & $\mathrm{f}_{f}$ & $\%$ & $f_{f}$ & $\%$ & $\mathrm{f}_{f}$ & $\%$ \\
\hline Favorecen totalmente sus actividades & 1 & 20,0 & & & & & 2 & 40,0 \\
\hline $\begin{array}{l}\text { Favorecen suficientemente sus } \\
\text { actividades }\end{array}$ & 1 & 20,0 & 1 & 20,0 & 1 & 20,0 & 1 & 20,0 \\
\hline $\begin{array}{l}\text { Ni favorecen ni desfavorecen sus } \\
\text { actividades }\end{array}$ & 1 & 20,0 & 1 & 20,0 & 1 & 20,0 & 1 & 20,0 \\
\hline $\begin{array}{l}\text { Desfavorecen insuficientemente sus } \\
\text { actividades }\end{array}$ & & & 3 & 60,0 & & & & \\
\hline Desfavorecen totalmente sus actividades & 1 & 20,0 & & & & & & \\
\hline Promedio & \multicolumn{2}{|c|}{ Indeterminado } & \multicolumn{2}{|c|}{$\begin{array}{c}\text { Desfavorecen } \\
\text { insuficientemente sus } \\
\text { actividades }\end{array}$} & \multicolumn{2}{|c|}{ Indeterminado } & \multicolumn{2}{|c|}{$\begin{array}{c}\text { Favorecen } \\
\text { suficientemente sus } \\
\text { actividades }\end{array}$} \\
\hline
\end{tabular}

Fuente: L. Castrillo y R. Espinoza (2018)

Compartir valores sociales y culturales conlleva a que las personas y las organizaciones a las que están integradas expresen disposición para resguardar y actuar en correspondencia con los valores que regulan la convivencia y dinámica social. En la Tabla No. 17 se recogen los datos referidos a los valores socio-culturales que se han reforzado en cada universidad como resultado de acuerdos establecidos en las tres universidades. De acuerdo a los académicos valores como el respeto, la solidaridad, la pluralidad, la convivencia, la tolerancia, la libertad, la equidad, la responsabilidad y la participación han sido reforzados y se reforzaran con la integración interuniversitaria.

Tabla 17. Valores Socioculturales Reforzados como resultado con los Acuerdos firmados

\begin{tabular}{|c|c|c|c|c|c|c|c|c|c|c|c|}
\hline \multirow[t]{2}{*}{ Valores } & \multicolumn{2}{|c|}{$\begin{array}{c}\text { Ningún } \\
\text { nivel }\end{array}$} & \multicolumn{2}{|c|}{ Insuficiente } & \multicolumn{2}{|c|}{$\begin{array}{c}\text { Medio } \\
\text { suficiente }\end{array}$} & \multicolumn{2}{|c|}{ Suficiente } & \multicolumn{2}{|c|}{$\begin{array}{l}\text { Totalmente } \\
\text { suficiente }\end{array}$} & \multirow[t]{2}{*}{ Mediana } \\
\hline & $f$ & $\%$ & $f_{i}$ & $\%$ & $f_{1}$ & $\%$ & $f_{f}$ & $\%$ & $\mathrm{f}_{f}$ & $\%$ & \\
\hline Respeto & & & 1 & 20,0 & & & 3 & 60,0 & 1 & 20,0 & Suficiente \\
\hline Justicia & & & 1 & 20,0 & 2 & 40,0 & 2 & 40,0 & & & Medio suficiente \\
\hline Solidaridad & & & 1 & 20,0 & 1 & 20,0 & 3 & 60,0 & & & Suficiente \\
\hline Pluralidad & & & 1 & 20,0 & 1 & 20,0 & 3 & 60,0 & & & Suficiente \\
\hline Convivencia & & & 1 & 20,0 & & & 4 & 80,0 & & & Suficiente \\
\hline Tolerancia & & & 1 & 20,0 & & & 4 & 80,0 & & & Suficiente \\
\hline Equilibrio & & & 1 & 20,0 & 2 & 40,0 & 2 & 40,0 & & & Medio suficiente \\
\hline libertad & & & 1 & 20,0 & 1 & 20,0 & 3 & 60,0 & & & Suficiente \\
\hline Bienestar & & & 1 & 20,0 & 2 & 40,0 & 2 & 40,0 & & & Medio suficiente \\
\hline Equidad & & & 1 & 20,0 & 1 & 20,0 & 3 & 60,0 & & & Suficiente \\
\hline Responsabilidad & & & 1 & 20,0 & & & 3 & 60,0 & 1 & 20,0 & Suficiente \\
\hline Participación & & & 1 & 20,0 & & & 4 & 80,0 & & & Suficiente \\
\hline
\end{tabular}

Fuente: L. Castrillo y R. Espinoza (2018) 


\section{Alcance del Proceso de Integración Interuniversitaria}

El alcance de la integración que se haya podido adelantar entre las universidades localizadas en la región de frontera venezolana-colombiana se puede estimar considerando varios indicadores: acuerdos para la producción de conocimiento, formulación de estrategias para la gestión de la transferencia y utilización del conocimiento, institucionalización de la transferencia de conocimiento entre las universidades, determinación de los tipos de conocimiento que se deben producir en las universidades orientado por los acuerdos entre ellas y tipos y niveles de aprendizaje colectivo.

\section{Producción de Conocimiento}

De acuerdo con la información suministrada por las tres universidades, éstas en el contexto de relaciones formales y en algunos casos de relaciones informales han compartido la ejecución de proyectos de investigación mayormente con propósitos académicos. En la Tabla No. 18 se recogen los datos respecto al tipo de conocimiento, de acuerdos a los académicos encuestados en principio los conocimientos sobre gestión académica, científica y tecnológica son de mayor probabilidad de transferencia.

Tabla 18. Proporción de los diferentes tipos de conocimiento que las universidades muestreadas producen y podrían transferir en el proceso de integración.

\begin{tabular}{|l|c|}
\hline Tipos de conocimiento & Mediana \\
\hline Conocimiento Científico & 26 a $50 \%$ \\
\hline Conocimiento Tecnológico & 26 a $50 \%$ \\
\hline Conocimiento Tecno-Científico & 26 a $50 \%$ \\
\hline Conocimiento de Mercado & 26 a $50 \%$ \\
\hline Conocimiento de producto/servicio & 26 a $50 \%$ \\
\hline Conocimiento sobre gestión A-C-T & 50 a $75 \%$ \\
\hline Fuente: L. Castrillo y R. Espinoza (2018).
\end{tabular}

La calidad del conocimiento que se genera a partir de la investigación está afectada positiva o negativamente por condiciones y factores que modelan la estructura del conocimiento construido. En la Tabla No. 19 se indican los niveles cualitativos, se presentan los indicadores de la calidad del conocimiento en el proceso de integración. El establecimiento de relaciones 
cognitivas entre diferentes ideas que se generan para la producción de conocimiento se destaca en la dinámica del proceso científico que se aborda en cada universidad.

Tabla 19. Niveles cualitativos presentes en los indicadores de la calidad del conocimiento en el proceso de integración

\begin{tabular}{|l|c|}
\hline Niveles de la calidad del conocimiento & Mediana \\
\hline Establecimiento de relaciones cognitivas entre diferentes ideas & Alta \\
\hline Construcción de redes cognitivas propositivas & Media \\
\hline Construcción de redes cognitivas comprensibles & Media \\
\hline
\end{tabular}

Fuente: L. Castrillo y R. Espinoza (2018).

Actualmente las universidades que han decido disponer de capacidad para producir nuevo conocimiento y avanzar en los procesos de innovación igualmente han decidido integrarse en redes interorganizacionales del tipo redes de conocimiento e innovación. En el caso de las tres universidades muestreadas de acuerdo a los datos presentados en la Tabla No 20 ellas refieren ser parte de redes de investigación interdisciplinarias y transdisciplinaria (51 a $75 \%$ ), este resultado hay que considerarlo con cautela, la observación directa realizada sobre las trayectorias de la creación de redes de investigación contradicen la valoración otorgada por las personas que respondieron el cuestionario dado que no se registran redes que hayan sido constituidas formalmente.

Tabla 20. Proporción de los tipos de redes de conocimiento; usadas. para transferir conocimiento actualmente en el proceso de integración.

\begin{tabular}{|l|l|}
\hline Redes de: & Mediana \\
\hline Investigación Interdisciplinaria & 51 a $75 \%$ \\
\hline Investigación Transdiciplinaria & 51 a $75 \%$ \\
\hline Innovación Tecnológica & 26 a $50 \%$ \\
\hline Desarrollo Tecnológico & 51 a $75 \%$ \\
\hline Gerencia del Conocimiento & 51 a $75 \%$ \\
\hline Transferencia y Comercialización de Conocimiento & 51 a $25 \%$ \\
\hline Construcción de Capacidad para el Desarrollo del Conocimiento & 51 a $75 \%$ \\
\hline Emprendimiento de Empresas de Base de Conocimiento y Tecnología & 51 a $75 \%$ \\
\hline
\end{tabular}

Fuente: L. Castrillo y R. Espinoza (2018). 


\section{Gestión de Conocimiento en la Integración Universitaria}

Considerar la integración de las universidades de frontera con sustento en la producción de conocimiento implica el acompañamiento de la gestión para soportar las diversas estrategias y acciones que ello implica. En la Tabla No 21 se puede observar que los docentes muestreados destacan la conducción de la gestión mediante la interacción virtual y las interacciones directas.

Tabla 21. Proporción de los diferentes tipos de gestión de conocimiento; que se aplican durante el proceso de integración

\begin{tabular}{|c|c|c|c|c|c|c|c|c|c|c|c|}
\hline \multirow[t]{2}{*}{ Tipos de gestión } & \multicolumn{2}{|c|}{ Ninguno } & \multicolumn{2}{|c|}{1 al $25 \%$} & \multicolumn{2}{|c|}{$\begin{array}{l}\mathbf{2 6} \text { al } \\
\mathbf{5 0} \%\end{array}$} & \multicolumn{2}{|c|}{$\begin{array}{l}51 \text { al } \\
75 \%\end{array}$} & \multicolumn{2}{|c|}{$\begin{array}{c}76 \text { al } \\
100 \%\end{array}$} & \multirow[t]{2}{*}{ Mediana } \\
\hline & $\mathbf{f}_{\mathrm{r}}$ & $\%$ & $f_{r}$ & $\%$ & $\mathbf{f}_{\mathrm{r}}$ & $\%$ & $\mathbf{f}_{\mathrm{r}}$ & $\%$ & $\mathbf{f}_{\mathrm{r}}$ & $\%$ & \\
\hline En red virtual & & & 1 & 20,0 & 1 & 20,0 & 1 & 20,0 & 2 & 40,0 & 50 a $75 \%$ \\
\hline Relaciones Directas & & & 1 & 20,0 & 1 & 20,0 & 3 & 60,0 & & & 50 a $75 \%$ \\
\hline Otra & & & & & & & & & & & No respondió \\
\hline
\end{tabular}

Fuente: L. Castrillo Y R. Espinoza(2018)

La gestión del conocimiento es un proceso complejo que contempla la realización de varias fases. En este sentido de acuerdo a los datos que se presentan en la Tabla No 22 en relación a las fases que se aplican en las universidades estudiadas, los niveles de gestión de las seis fases son valoradas medianamente suficiente, esto significa que existe debilidad en la actuación de las dependencias encargadas de organizar y ejecutar la gestión de manera integral.

Tabla 22. Nivel se encuentra el proceso de gestión de conocimiento que se da durante el proceso de integración

\begin{tabular}{|c|c|c|c|c|c|c|c|c|c|c|c|}
\hline \multirow[t]{2}{*}{ Fases de la gestión } & \multicolumn{2}{|c|}{ Ningún } & \multicolumn{2}{|c|}{ Insuficiente } & \multicolumn{2}{|c|}{$\begin{array}{c}\text { Medio } \\
\text { suficiente }\end{array}$} & \multicolumn{2}{|c|}{ Suficiente } & \multicolumn{2}{|c|}{$\begin{array}{l}\text { Suficiente } \\
\text { total }\end{array}$} & \multirow[t]{2}{*}{ Mediana } \\
\hline & $f_{r}$ & $\%$ & $\mathbf{f}_{\mathrm{r}}$ & $\%$ & $\mathbf{f}_{\mathrm{r}}$ & $\%$ & $\mathbf{f}_{\mathrm{r}}$ & $\%$ & $f_{r}$ & $\%$ & \\
\hline Capturar conocimiento & & & 1 & 20,0 & 3 & 60,0 & 1 & 20,0 & & & $\begin{array}{l}\text { Medio } \\
\text { suficiente }\end{array}$ \\
\hline Crear conocimiento & & & 1 & 20,0 & 3 & 60,0 & 1 & 20,0 & & & $\begin{array}{c}\text { Medio } \\
\text { suficiente }\end{array}$ \\
\hline $\begin{array}{l}\text { Almacenar } \\
\text { conocimiento }\end{array}$ & & & 1 & 20,0 & 3 & 60,0 & 1 & 20,0 & & & $\begin{array}{c}\text { Medio } \\
\text { suficiente }\end{array}$ \\
\hline Distribuir conocimiento & & & 2 & 40,0 & 1 & 20,0 & 2 & 40,0 & & & $\begin{array}{l}\text { Medio } \\
\text { suficiente }\end{array}$ \\
\hline Certificar Conocimiento & & & 1 & 20,0 & 3 & 60,0 & & & 1 & 20,0 & $\begin{array}{l}\text { Medio } \\
\text { suficiente }\end{array}$ \\
\hline Reponer Conocimiento & & & 1 & 20,0 & 3 & 60,0 & 1 & 20,0 & & & $\begin{array}{c}\text { Medio } \\
\text { suficiente }\end{array}$ \\
\hline
\end{tabular}


Un hecho que hay que resaltar y que destacan los docentes encuestados es la presencia de obstáculos para desarrollar la gestión del conocimiento, en la Tabla No 23 se puede observar la poca atención que se le ha prestado a la creación y consolidación de una infraestructura institucional y administrativa para desarrollar un proceso que es de vital importancia para conducir la producción y transferencia de conocimiento ya sea internamente o externamente como es el caso de la integración interuniversitaria.

Tabla 23. Proporción en que se presentan los diferentes obstáculos para gestionar conocimiento en el proceso de integración

\begin{tabular}{|c|c|c|c|c|c|c|c|c|c|c|c|}
\hline \multirow[t]{2}{*}{ Obstáculos } & \multicolumn{2}{|c|}{ 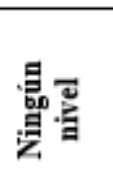 } & \multicolumn{2}{|c|}{ 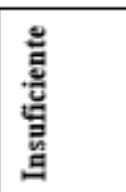 } & \multicolumn{2}{|c|}{ 承䓌 } & \multicolumn{2}{|c|}{ 总 } & \multicolumn{2}{|c|}{ 总 } & \multirow[t]{2}{*}{ Mediana } \\
\hline & $f_{\mathrm{f}}$ & $\%$ & $\mathrm{f}_{f}$ & $\%$ & $f_{f}$ & $\%$ & $f_{x}$ & $\%$ & $\mathrm{f}_{t}$ & $\%$ & \\
\hline Recursos económicos. escasos & & & 1 & 20,0 & 1 & 20,0 & & & 3 & 60,0 & Suficiente total \\
\hline Escasos activos & & & 1 & 20,0 & 1 & 20,0 & 2 & 40,0 & 1 & 20,0 & Suficiente \\
\hline Dificultad para obtener activos & & & 2 & 40,0 & 1 & 20,0 & 1 & 20,0 & 1 & 20,0 & Medio suficiente \\
\hline $\begin{array}{l}\text { Tramitación excesiva para gestionar } \\
\text { conocimiento }\end{array}$ & & & 2 & 40,0 & & & 2 & 40,0 & 1 & 20,0 & Suficiente \\
\hline Infraestructura Institucional Inexistente & & & 1 & 20,0 & 3 & 60,0 & 1 & 20,0 & & & Medio suficiente \\
\hline Infraestructura Tecnológica Insuficiente & & & 2 & 40,0 & 2 & 40,0 & 1 & 20,0 & & & Medio suficiente \\
\hline $\begin{array}{l}\text { Falta de Experticia Profesional para } \\
\text { Gestionar la Transferencia }\end{array}$ & 1 & 20,0 & 3 & 60,0 & & & 1 & 20,0 & & & Insuficiente \\
\hline
\end{tabular}

No obstante, los obstáculos que presentan las tres universidades para gestionar el conocimiento, los docentes muestreados reconocen los propósitos que se lograrían las implicaciones que se tendría el proceso de integración. En la Tabla No 24 se destaca de manera significativa tres importantes propósitos: incorporar conocimiento al mercado, compartir conocimiento con los miembros del proceso de integración y generar una mayor cultura de la integración. 
Tabla 24. Proporción de los diferentes propósitos en la gestión de conocimiento; que se tienen en el proceso de integración

\begin{tabular}{|c|c|c|c|c|c|c|c|c|c|c|c|}
\hline \multirow[t]{2}{*}{ Propósito } & \multicolumn{2}{|c|}{$\begin{array}{l}\text { Menos } \\
10 \%\end{array}$} & \multicolumn{2}{|c|}{$\begin{array}{c}10 \% \text { a } \\
40 \%\end{array}$} & \multicolumn{2}{|c|}{$40 \%$ a $60 \%$} & \multicolumn{2}{|c|}{$\begin{array}{c}60 \% \text { a } \\
80 \%\end{array}$} & \multicolumn{2}{|c|}{$\begin{array}{c}\text { Más de } \\
80 \%\end{array}$} & \multirow[t]{2}{*}{ Mediana } \\
\hline & $\mathbf{f}_{\mathrm{r}}$ & $\%$ & $\mathbf{f}_{\mathrm{r}}$ & $\%$ & $\mathbf{f}_{\mathrm{r}}$ & $\%$ & $\mathbf{f}_{\mathrm{r}}$ & $\%$ & $\mathbf{f}_{\mathrm{r}}$ & $\%$ & \\
\hline Incorporar conocimiento al mercado & & & 1 & 20,0 & 1 & 20,0 & 2 & 40,0 & 1 & 20,0 & 60 a $80 \%$ \\
\hline Comercializar el conocimiento & 1 & 20,0 & & & 3 & 60,0 & & & & & 40 a $60 \%$ \\
\hline $\begin{array}{l}\text { Compartir conocimiento con } \\
\text { miembros del proceso de integración }\end{array}$ & 1 & 20,0 & 1 & 20,0 & & & 1 & 20,0 & 2 & 40,0 & 60 a $80 \%$ \\
\hline $\begin{array}{l}\text { Generar una mayor cultura de la } \\
\text { integración }\end{array}$ & 1 & 20,0 & 1 & 20,0 & & & 2 & 40,0 & 1 & 20,0 & 60 a $80 \%$ \\
\hline $\begin{array}{l}\text { Obtener Ingresos Económicos y } \\
\text { Recursos Diversos para la } \\
\text { Universidad }\end{array}$ & 1 & 20,0 & 2 & 40,0 & 1 & 20,0 & & & 1 & 20,0 & 10 a $40 \%$ \\
\hline
\end{tabular}

Fuente: L. Castrillo y R. Espinoza (2018)

Entre las razones que explican la tendencia mundial de las universidades para formalizar relaciones se menciona la necesidad que ellas tienen de disponer de nuevo conocimiento para generar nuevo conocimiento y para desarrollar innovaciones. En relación con ello resaltan la conveniencia de llevar a cabo acuerdos de transferencia de conocimiento. En el caso de la integración de las universidades localizadas en la frontera venezolana y colombiana, se estima que la producción e inter-transferencia de conocimiento entre ellas favorecería la integración. En la Tabla No 25 se recogen los datos referidos a los medios utilizados para transferir conocimientos; en el proceso de integración universitario, al que pertenece la organización que usted representa. La licencia de patentes por el impacto que tiene en el valor científico. tecnológico y financiero de cada universidad es reconocido por los académicos.

Tabla 25. Proporción en el empleo de los medios utilizados para transferir conocimientos; en el proceso de integración universitario

\begin{tabular}{|c|c|c|c|c|c|c|c|c|c|c|c|}
\hline \multirow[t]{2}{*}{ Medios } & \multicolumn{2}{|c|}{ Ningún } & \multicolumn{2}{|c|}{$\begin{array}{l}1 \text { al } \\
25 \%\end{array}$} & \multicolumn{2}{|c|}{$\begin{array}{l}\mathbf{2 6} \text { al } \\
\mathbf{5 0} \%\end{array}$} & \multicolumn{2}{|c|}{$\begin{array}{l}\mathbf{5 1} \text { al } \\
\mathbf{7 5} \%\end{array}$} & \multicolumn{2}{|c|}{$\begin{array}{c}76 \text { al } \\
100 \%\end{array}$} & \multirow[t]{2}{*}{ Mediana } \\
\hline & $f_{r}$ & $\%$ & $f_{r}$ & $\%$ & $f_{r}$ & $\%$ & $f_{r}$ & $\%$ & $f_{r}$ & $\%$ & \\
\hline Licencias de Patentes & & & 2 & 40,0 & & & 1 & 20,0 & & & 50 a $75 \%$ \\
\hline Cesión de Resultados de Investigación & & & 2 & 40,0 & 1 & 20,0 & & & 1 & 20,0 & 25 a $50 \%$ \\
\hline $\begin{array}{l}\text { Capital Asociado para la Producción de } \\
\text { Conocimiento }\end{array}$ & & & 2 & 40,0 & 1 & 20,0 & 1 & 20,0 & 1 & 20,0 & 25 a $50 \%$ \\
\hline $\begin{array}{l}\text { Financiamiento Externo para la Investigación } \\
\text { de las Universidades en Red }\end{array}$ & & & 2 & 40,0 & 1 & 20,0 & 1 & 20,0 & 1 & 20,0 & 25 a $50 \%$ \\
\hline Otro & & & & & & & & & & & No respondió \\
\hline
\end{tabular}

Fuente: L. Castrillo y R. Espinoza (2018) 
Dado el hecho que la Universidad del Zulia, la Universidad Popular del Cesar y la Universidad de la Guajira han suscrito convenios marco para relacionarse académicamente se exploró si han llevado a cabo procesos de transferencia de conocimiento de manera recíproca. En la Tabla No 26 se presentan valores respecto a la información emitida por los académicos muestreados que deben ser considerados con reserva en cuanto a su correspondencia con la realidad. Al observar particularmente en el contexto de la Universidad del Zulia no existen registros formales de transferencia de conocimiento y por tanto de reciprocidad.

Tabla 26. Proporción de participación en la reciprocidad para la transferencia del conocimiento entre universidades-regiones; en el proceso de integración universitario.

\begin{tabular}{|c|c|c|c|c|c|c|c|c|c|c|c|c|}
\hline \multirow[t]{2}{*}{ Región } & \multirow[t]{2}{*}{ Región } & \multicolumn{2}{|c|}{ Ninguno } & \multicolumn{2}{|c|}{1 al $25 \%$} & \multicolumn{2}{|c|}{26 al 50\% } & \multicolumn{2}{|c|}{ 51 al 75\% } & \multicolumn{2}{|c|}{$\begin{array}{c}76 \text { al } \\
100 \%\end{array}$} & \multirow[t]{2}{*}{ Mediana } \\
\hline & & $f$ & $\%$ & $f$. & $\%$ & $f$ & $\%$ & $f$ & $\%$ & $f$ & $\%$ & \\
\hline \multirow[t]{2}{*}{ CESAR } & GUAJIRA & & & & & $\frac{1}{2}$ & 40,0 & 1 & 20,0 & 1 & 20,0 & 50 a $75 \%$ \\
\hline & ZULIA & & & & & & & 4 & 80,0 & & & 50 a $75 \%$ \\
\hline \multirow[t]{2}{*}{ GUAJIRA } & CESAR & & & & & 1 & 20,0 & 1 & 20,0 & 1 & 20,0 & 75 a $100 \%$ \\
\hline & ZULIA & & & 3 & 60,0 & & & & & & & 1 a $25 \%$ \\
\hline & & & & & & & & & & & & \\
\hline \multirow[t]{2}{*}{ ZULIA } & CESAR & & & 1 & 20,0 & & & 2 & 40,0 & & & 50 a $75 \%$ \\
\hline & GUAJIRA & & & & & 1 & 20,0 & 2 & 40,0 & & & 50 a $75 \%$ \\
\hline
\end{tabular}

Fuente: L. Castrillo y R. Espinoza (2018)

\section{Conclusiones}

La observación de la realidad empírica constituida por el contexto interfronterizo venezolano-colombiano y particularmente el diagnóstico del inter contexto de las universidades ubicadas en el espacio interfronterizo: Universidad del Zulia, Universidad de la Guajira y Universidad Popular del Cesar, con la guía del sistema teórico construido permite formular las siguientes conclusiones, las cuales constituyen lineamientos para la arquitectura prospectiva de la integración.

Visualizar la integración de las universidades de frontera venezolana-colombiana conlleva el diseño de un proceso de reflexión teórica, dicho proceso implica la disposición de códigos, conceptos y lineamientos teóricos por parte de los representantes de las 
universidades a fin de fundamentar el diálogo, las divergencias y las convergencias que llevarán a la construcción colectiva del paradigma que guiará las estrategias para iniciar el complejo proceso de integración.

La previa elaboración colectiva del paradigma para la integración de la región interfronteriza y de continuo la interiorización del mismo por los actores universitarios y los agentes sociopolíticos y socioeconómicos locales son factores fundamentales para disponer de viabilidad para el proceso de integración.

La disposición de viabilidad teórica consensuada entre los actores universitarios y los agentes del entorno interfronterizo es la palanca que conllevará a la reflexión prospectiva respecto a la integración académica y científica de la Universidad del Zulia, la Universidad de la Guajira y de la Universidad Popular del Cesar.

Finalmente se registra que de acuerdo a los juicios emitidos por los académicos si bien no se ha avanzado en el proceso de integración entre las universidades, existen un contexto sociocultural y socio-académico favorable para desplegar propuestas la integración interuniversitaria con soporte en estructuras reticulares que conlleven a la producción y transferencia de conocimiento e innovación tecnológica. De igual manera se puede señalar que existe gran consenso en la necesidad de la integración para llegar a niveles de internacionalización de las universidades localizadas en la región de frontera venezolanacolombiana. 


\section{Referencias}

BANCO INTERAMERICANO DE DESARROLLO. (1964): Posibilidades de integración fronteriza colombo- venezolana. (Documento, publicado por el BID)

CONGRESO de la República de Venezuela. Ley de Universidades. Gaceta oficial No1429 Extraordinaria. 8 de septiembre de 1970

Luhmann, Niklas (2005): Confianza. Editorial: ANTHROPOS. Barcelona. España

Mauss, Marcel (2002: The Gift. The form and reason for exchange in archaic societies. Edit. Routledge. London

Mayer, Roger; Davis, James H.; Shoorman, F. David, (1995) An Integration model of organizational trust, Academy of Management Review.

UNESCO, (2009) Conferencia Mundial de Educación Superior:” la nueva Dinámica de la educación superior y la búsqueda del cambio social y el desarrollo" Paris, Francia. 